\title{
Peculiarities of Teaching Aesthetics to Students with Hearing Disabilities and to Hearing-impaired Students
}

\author{
Natalia Didenko \\ Humanities Department \\ Russian State Specialized Academy of Fine Arts \\ Moscow, Russia
}

\begin{abstract}
The work reviews the specifics of teaching aesthetics to students with hearing disabilities and to the hearing impaired students of the Arts and Theatrical Department of the Russian State Specialized Academy of Fine Arts (RGSAI). The goal of the course is to develop students' imaginative and logical thinking, to help the latter learn material through accessible non-verbal forms of communication. The course is taught to the hearing-impaired students with a significant involvement of a sign language interpreter. The author analyzes the importance of aesthetics as a subject is directly related to the practical and creative experience of students, the development of ideology, aesthetic taste and sensitivity.
\end{abstract}

Keywords-aesthetics; creativity; sign language; thinking; art; verbal and non-verbal; personality; perception

\section{INTRODUCTION}

The teaching of aesthetics in such university like RGSAI, with its theatrical, musical and arts departments, is of a particular importance. By making students learn the science of aesthetics the university creates a base for the development of ideas and knowledge about general rules of aesthetic perception of the world by a human being, structure and development laws of the sense of art in society and personality, arts and creativity.

The course of aesthetics demonstrates the importance of the aesthetic phenomenon in various areas of human activity, both in the historical context and in the context of the most important problems of modern aesthetics and art; it shows that there are some "universal" traits in the relationship of a human being and the world, that these traits remain significant for almost the entire history of a human being a civilized creature. The field of aesthetics belongs to these essential characteristics of a cosmoatropic existence, which is the very subject of the aesthetics science.

The key method and form of getting a deeper knowledge of aesthetics is art and artistic creativity, which is to what our students dedicate their time. That is why one of our most important pedagogical tasks is to demonstrate the specifics of how art functions. Here we primarily talk about theater, music, and fine arts in different cultural-historical epochs.
These three elements form the trinity of the artistic creation as well as show the act of creativity and artistic perception through the uniqueness of each aesthetic phenomenon.

It is also important to explain the current situation that formed around the theory dealing with postmodernism. Based on the modern concept of the Humanities, there is a belief that it destroys the classical forms of art, the completeness and uniqueness of the artistic creativity, authorship, professionalism, etc

It is clear that it is quite difficult to reach these goals, especially when we are talking about didactic methods and techniques of working with students with hearing disabilities and hearing impaired students.

\section{MAIN PROBLEMS OF HUMANITARIAN EDUCATION FOR STUDENTS WITH HEARING DISABILITIES AND FOR HEARING IMPAIRED STUDENTS}

The Humanities subjects taught at RGSAI and, in particular, aesthetics, gives our students the general cultural and ideological base. Our goal is to compensate for the problems that are typical for the cognitive activity of our students by giving them knowledge and the empathic participation of the teachers. In addition, we aim to provide them with a system of values that will help them not only to overcome difficult life situations, but at the same time to solve problems connected with art. We believe that the Humanities subjects taught at the faculty, among which aesthetics plays a key role, should particularly contribute to the achievement of the following educational objectives:

- Learning about the basic values of the world and Russian culture, and willingness to rely on them in one's personal and overall cultural development;

- Developing a culture of thinking, ability to perceive, compile and analyze information, set a goal and choose a way of its achievement;

- Learning to form oral and written speech in a logical way, with proper reasoning and arguments;

- Learning to cooperate with colleagues and work in a team; 
- Learning the skill of self-development, improvement of one's qualifications and skills;

- Ability to critically assess personal strengths and weaknesses;

- Ability to adhere to ethical values and healthy lifestyle;

- Ability to analyze and build interpersonal, group and organizational communications;

- ability to collect the necessary data without anybody's help, using only Russian and foreign sources of information;

- Ability to analyze various sources of information, prepare a report, or an information review of a seminar or student scientific conference.

Now let us take a look at the actual problems that can take place while teaching students with hearing disabilities, and the ways of solving them. Students with hearing disabilities and hearing impaired students have to overcome a number of difficulties to become professionals in the specialist discipline they have chosen, successfully finish their education and to become specialists with the higher education in arts.

Students with hearing disabilities study at two RGSAI faculties - the faculty of fine arts and the theatrical faculty. The first difficulty faced by the students relate to the necessity to learn the sign language, to be able to adequately understand the sign language interpreter. This necessity arises because students come from different regions of Russia, where there are some conversational peculiarities with the help of sign language. Often students speak the dactyl (the pronunciation of the letters). All this makes speaking difficult and requires special knowledge to be able to learn sign language.

Sign language is taught at RGSAI as a separate subject, where experts teach students how to relate sign language with functional verbal language, they also teach them to use gestures to be able to succeed in their education, reach their educational goals and expand their vocabulary. There is an effective method to make it easier for the students to learn the subjects taught during their first year. Teachers work in a close contact with sign language interpreters, they give them a list of terms - words required for use during the future classes, they discuss the definitions and interpretation of these terms. This way, when a student with hearing disabilities starts to learn these terms, for example, as part of the aesthetics class, he or she will only need to revise his or her knowledge and put these terms in a specific context. The difficulties that hearing impaired students experience while learning about the world around them and while studying the training material, first and foremost, come from the specifics of the students' way of thinking. They cannot hear and the difference sounds around them are not available to them. That is why the most important goal of their education is to develop and form analytical skills, ability for synthesis, abstract and figurative thinking. The Humanities subjects (primarily aesthetics) are designed to solve this problem.
Thinking is closely associated with gestures. Approximately $50 \%$ of information we receive is in a form of facial expressions, gestures, i.e. non-verbal forms of communication; and this potential needs to be used.

The key goal for a student with hearing disabilities is to learn sign language. That is why we teach sign language as a separate subject. The role of a sign language interpreter is very important when working with students with hearing disabilities and hearing impaired students. Professional explanation of terms, associations given to students by a sign language interpreter, his or her caring attitude to each student, desire to explain in detail all the things that the teacher said, allows to expand the horizons of students with hearing disabilities and helps them to become creative individuals who can live their lives in full. It can be said that a teacher, together with a sign language interpreter, develops and forms the way of thinking of a student. All the Humanities classes at RGSAI contribute to this.

The aesthetics, the philosophy of art, however, presents the subject dealing directly with students' practical and creative experiences, and plays a special role in development of their way of perceiving the world and sensing beauty. That is why these subjects are of particular importance for students with hearing disabilities. The way of interacting, how in tuned with each other the teacher and the sign language interpreter are, are particularly important. If a clarification of a term is needed, a break is taken. At the end of each lecture students write down all unfamiliar and complex words. The necessary condition for the successful learning of the subject is student's self-study of vocabulary. During such homework, he or she deciphers these words, accompanying it by appropriate gestures. Each student with hearing disabilities has a notebook where he or she writes down the terms. This helps students to select and memorize the terms in the most optimal way.

If students do not know the terms and lack vocabulary, it makes it more difficult to study the Humanities subjects, in particular, the foundations of aesthetics. To solve this problem, it is necessary to pay special attention to what terms mean, to update the glossary, to clarify the terms through the sign language interpreters, and in particular, prepare answers to the questions in sign language. To learn material better, students with hearing disabilities should make sure they actively read different types of literature.

It should be noted that this problem is typical not only for students with hearing disabilities and hearing impaired students, but also for students without such disabilities.

\section{Methodology Base of Teaching Aesthetics to STUDENTS WITH HEARING DISABILITIES AND HEARING IMPAIRED STUDENTS}

In the era of computer technologies, reading becomes less and less popular. However, for people with hearing disabilities reading is a tool for an in-depth understanding of meanings. That is why it is necessary form a motivation for reading, both internally and externally, to develop an understanding that there is a need to learn about unfamiliar, 
abstract concepts and terms, to increase the level of your knowledge.

Sometimes by the end of the course the most active hearing impaired students succeed in learning every term, even the complex philosophical and aesthetic terminology. However, it requires a lot of hard work.

Lack of basic knowledge that hearing impaired students have is one of the major factors making it difficult to get a full education. Even students that hear often do not have sufficient level of knowledge to feel comfortable during the lectures and seminars of the Humanities courses. Both hearing students and students with hearing disabilities should be striving for big internal work in order to succeed in such discipline as aesthetics. Intensive reading of special texts is needed, as well as it is necessary to learn to use your knowledge and experience gained while studying specialist disciplines and during your primary activities (e.g., on the stage or when drawing).

Basically, it is necessary to accumulate and apply all the knowledge acquired during the 4-6 years of university studies.

For students with hearing disabilities it is considered to be an effective learning model to base the learning process around the primary sources of information and the original texts. During the first year of studies all faculties use this approach, for example, during such lessons as Russian language, the culture of speech, and literature. During the more senior years of education, when studying aesthetics, this approach is used by making students read texts by Plato, Aristotle, D. Diderot, N. Boileau, P. della Mirandola, Th. Aquinas, F. Nietzsche, A. Schopenhauer, P. Florensky, V. Solovyov and others, and then discuss them during seminars.

It is important to teach students to express their opinion on any subject thoroughly and in a convincing manner, to draw parallels, to use all the knowledge acquired up to this moment, to teach them to think and make conclusions.

Various disciplines complement each other. Knowledge that hearing impaired students get while studying the Humanities, create one whole system, a certain picture of the world, of the environment, and gives direction in life. This said, topics studied in such classes like history and history of art can be used during the history of religion and aesthetics seminars, and vice versa.

Such more detailed knowledge is particularly necessary for the hearing impaired students. This allows them to clarify any term, to expand their knowledge and horizons, to expand their vocabulary, all of which helps to develop both imaginative and logical thinking. During seminars, student actors seek to discuss questions as a whole group, in a very emotional manner, actively engaging in polemics. Such collective approach should be valued because this trait of behavior is common to all actors; they are used to working together and helping each other. However, it is also necessary to develop the individual traits of character in each student. By the time of graduation, each student with hearing disabilities and hearing impaired student should be able to make quite in-depth and independent analysis of a text suggested by the teacher.

On the contrary, student artists prefer to work individually because the nature of their profession forms these preferences in them. This explains the difficulties with the organization of seminars in groups that have students from the faculty of fine arts. For such students it is also difficult to communicate with their co-students and to develop proper dialogue. Everyone should understand each other and not repeat but correct and amend what is being heard during lectures and seminars.

The key, and an extremely difficult, goal for the students with hearing disabilities and hearing impaired students is to explain the meaning of a sound, its nature and connection with the peculiarities of the perception of the world. To reach this goal, it is necessary to use examples taken from those types of art that are familiar to students; for example, images and themes from the visual arts and literature. It is necessary to expand this association list not only during the aesthetics class, but also during other Humanities classes: history, history of religion, history of theatre, history of foreign literature, history of Russian literature, etc.

Only by joint efforts, we can teach the hearing impaired students to understand the sound. To succeed in this, it is extremely important to teach them about music as a type of sound art. Those students who preserved residual hearing can listen to music. For those students who do not have residual hearing, the main method of learning about the sound is an active learning of theory, as well as associations.

It is great when during an exam on aesthetics a student with hearing disabilities shows his or her knowledge about the art of music. It proves his or her extended knowledge, the development of the aesthetic feeling and thinking.

The way the Humanities courses are structured in our Academy is very important. During the first year of studying, students learn sign language, study Russian language, history of religion, and cultural studies. During the second and third years of studying, they learn about the history of theatre, history of fine art, history of costume. During the last years of studying, students with hearing disabilities and hearing impaired students study aesthetics that helps them to synthesize all of their cultural knowledge, bring it into a system, which helps to form a more or less complete understanding of the world.

The heuristic potential and the effectiveness of our methodology shows itself well enough at the state exams testing the theoretical part of a student's specialist discipline (such as acting, history of theatre, history of art and aesthetics). For example, students use their knowledge of aesthetics when explaining the Method acting, the great concept of Plato and other classics of ancient aesthetics. Based on the peculiarities of the ancient theater, they show the aesthetic essence of symbolism; based on the works of M. A. Vrubel, they assess the socio-cultural situation in Russia in the late 19th century, referring to the works of artists called the Wanderers. 


\section{CONCLUSION}

It is clear that the lectures on aesthetics should be presented in a form of presentations; hence, it is necessary to equip the auditoriums, where lectures and seminars are held, with all the necessary equipment. Today the auditoriums of the Academy are equipped with modern equipment necessary to organize presentations.

The video materials are essential for all students, but it is especially important for students with hearing disabilities, because videos expands and enhances the theoretical knowledge, provides them with the necessary clarity and specifics, helps to develop creative thinking. For example, illustrations accompanying the lecture on "the Aesthetics of Romanticism" introduce students to the founders of this course, give them an understanding of the aesthetic values and the ideals of romanticism, allow them to visualize the information available about Western European direction in art and the works of Delacroix, Géricault, Runge, and Russian romanticism: Kirensky, Orlovsky, etc. Lectures with video presentations impress the hearing impaired students and help them to learn the diverse material.

\section{REFERENCES}

[1] Actualization of cognitive activities of the hearing impaired students and students with hearing disabilities, Collection of scientific works, E. I. Andreev (ed.), L.: Leningrad Pedagogical University named after A. Herzen, 1973, p. 156.

[2] I. M. Vostrov, V. P. Kameneva, V. E. Romashkina, From the language of the streets to the sign language // Artistic education and science, 2015. No. 1, pp. 50-55.

[3] N. S. Didenko. Spetsifika prepodavaniya tsikla gumanitarnikh distsiplin na kafedre arterskogo masterstva // Sbornik statey mezhdunarodnoy nauchno-prakticheskoy konferentsii "Teatral'noe obrazovanie dlya lyudey s narusheniem slukha" [Specifics of teaching the Humanities classes at the acting faculty // Collection of articles for the International Scientific-practical conference "Theatre education for people with hearing disabilities"]. - M., 2011. P. 12-17.

[4] S. A. Zurabian, Cooperation in education as the means of improving the effectiveness of teaching students with hearing disabilities, Thesis, M., p. 204.

[5] V. V. Kalizky, On the role of semiotic concept when teaching students the course "A drama theater actor", Collection of articles for the International Scientific-practical conference "Theater education for people with hearing disabilities", M., 2011, pp. 22-25. 